\title{
Development of a disease specific health related quality of life measure for adults and adolescents with cystic fibrosis
}

\author{
L Gee, J Abbott, S P Conway, C Etherington, A K Webb
}

\begin{abstract}
Background-Health related quality of life (HRQoL) measurement is important in determining the impact of disease on daily functioning and subsequently informing interventions. In cystic fibrosis (CF) generic HRQoL measures have been employed but these may not be sufficiently specific. The aim of the current work was to develop and validate a disease specific HRQoL measure for adults and adolescents with cystic fibrosis.
\end{abstract}

Methods-Areas of concern to adults and adolescents with CF were identified by unstructured interviews, selfadministered questionnaires, consultation with multidisciplinary specialist staff, a review of the relevant literature, and examination of other HRQoL measures. Items for the questionnaire were generated on the basis of this process. Continued evaluation and development of the Cystic Fibrosis Quality of Life (CFQoL) questionnaire was undertaken by a process of statistical analysis and continued feedback from patients. The full testing and validation of the CFQoL questionnaire took place over four phases: (1) initial item generation and testing of a preliminary questionnaire, (2) testing and validation of the second version of the questionnaire, (3) test-retest reliability of a third and final version of the questionnaire, and (4) sensitivity testing of the final version of the questionnaire.

Results-Nine domains of functioning were identified using principal components analysis with varimax rotation. Internal reliability of the identified domains was demonstrated using Cronbach alpha coefficients (range 0.72-0.92) and item to total domain score correlations. Concurrent validity (range $r=0.64-0.74$ ), discriminatory ability between different levels of disease severity, sensitivity across transient changes in health (effect size range, moderate $d=0.56$ to large $d=1.95$ ), and test-retest reliability $(r=0.74-0.96)$ were also found to be robust.

Conclusions-The CFQoL questionnaire is a fully validated disease specific measure consisting of 52 items across nine domains of functioning which have been identified by, and are of importance to, adolescents and adults with cystic fibrosis. This measure will be useful in clinical trials and longitudinal studies.

(Thorax 2000;55:946-954)
Keywords: health related quality of life; questionnaire; cystic fibrosis

Advances in the care and treatment of cystic fibrosis (CF) have resulted in most patients surviving into adulthood. ${ }^{1}$ Despite these improvements, CF remains a progressive and ultimately fatal multisystem disease that has a heavy treatment regimen. ${ }^{2}$ Given this, a new goal for intervention in CF should be to measure and improve health related quality of life (HRQoL) in relation to medical and psychosocial interventions. The measurement of HRQoL complements clinical measures of disease status such as respiratory function tests. Once developed a questionnaire would be useful as (a) an outcome measure in clinical trials, (b) for the assessment of disease progression, and (c) for the monitoring of individual patients.

To date, HRQoL in adults with $\mathrm{CF}$ has been measured using either generic scales $^{3-5}$ or disease specific respiratory measures. ${ }^{6-9}$ These measures were not developed for the CF population and are limited since they do not reflect areas of functioning that are particularly salient to the adult with CF. Because of this the data are likely to lack sensitivity and be problematic in their interpretation. This work aims to develop, test, and validate a disease specific measure of HRQoL for adults and adolescents with CF. The measure should include areas of functioning that are meaningful to adults with CF, be brief enough to be applied in a clinical setting (that is, completion time of about 10 minutes), be simple to administer and score (for use in clinical settings and postal surveys), and be sensitive enough to detect both changes in health within the individual and differences between levels of disease severity.

The development, testing, and validation of the Cystic Fibrosis Quality of Life (CFQoL) questionnaire took place over four phases: (1) initial item generation and testing of a preliminary questionnaire; (2) testing and validation of a second version of the questionnaire including concurrent and discriminative validity; (3) test-retest reliability of a third and final version of the questionnaire; and (4) sensitivity testing of the final version of the questionnaire. The step by step development and validation of the CFQoL is reflected in the structure of this paper with the various methods and results sections reported in sequential order for each stage of development and testing.

\footnotetext{
11 July 2000

Accepted for publication

8 August 2000

Received 1 February 2000

Returned to authors

10 April 2000
} 
Phase 1: Initial item generation and testing of a preliminary questionnaire METHODS

Generation of an initial list of items likely to be important to adults with CF was informed by the following processes: (1) consideration of the general literature exploring HRQoL, (2) literature dealing with the psychosocial and physiological aspects of CF, (3) examination of existing generic and respiratory specific questionnaires, (4) the outcome of interviews with $60 \mathrm{CF}$ adults conducted during the course of previous research ${ }^{10}$ which outlined areas of concern to them, (5) examination of the literature exploring HRQoL in CF, and (6) discussions with multidisciplinary staff from two specialist CF centres. These suggested several areas for inclusion in the questionnaire including physical functioning, social functioning, CF specific issues (chest symptoms, treatment, and body image), interpersonal relationships, career/college issues, and concerns for the future. Fifty items were constructed to represent these areas. Responses to the questionnaire were measured by a six point Likert scale ranging from $1=$ very strongly agree to $6=$ very strongly disagree. The response scale was arbitrary in a bid to encourage patients to suggest the most appropriate method of responding. A final screening item asked patients to report what they found most troublesome about their CF. This was included to ascertain whether any salient issues had been omitted. This initial questionnaire was designed as a framework from which items could be removed or added to in subsequent versions.

PATIENTS AND PROCEDURE

One hundred and five patients were recruited via the outpatient clinic of a specialist adult $\mathrm{CF}$ unit. Patients were randomly approached during routine visits and asked for consent to participate in the development of the questionnaire. The researcher had no prior knowledge of the patients or of their medical status. There was no 'a priori' exclusion of any patient attending the clinic on any grounds. To encourage genuine and meaningful responses no demographic or clinical details were taken for this initial and important phase of development. ${ }^{11}$ Patients self-completed the questionnaire which took approximately 10 minutes. Following completion, each patient was asked to comment on and criticise the

Table 1 Cronbach alpha coefficients of domains 1 to 9 of the CFQoL1 and comparative domains of the CFQoL2

\begin{tabular}{|c|c|c|c|c|}
\hline \multirow[b]{2}{*}{ Domain } & \multicolumn{2}{|l|}{ CFQoL1 } & \multicolumn{2}{|l|}{ CFQoL2 } \\
\hline & No of items & $\begin{array}{l}\text { Alpha } \\
\text { coefficient }\end{array}$ & No of items & $\begin{array}{l}\text { Alpha } \\
\text { coefficient }\end{array}$ \\
\hline Physical functioning & 10 & 0.90 & 10 & 0.92 \\
\hline Social functioning & 3 & $0.69 \dagger$ & 4 & 0.89 \\
\hline Treatment issues & 2 & 0.81 & 3 & 0.89 \\
\hline Chest symptoms & 2 & 0.84 & 2 & 0.83 \\
\hline Emotional responses & Not applicable & & 8 & 0.91 \\
\hline Concerns for the future & 6 & 0.82 & 6 & 0.83 \\
\hline Interpersonal relationships & 8 & 0.90 & 10 & 0.90 \\
\hline Body image & 2 & 0.68 & 3 & 0.72 \\
\hline Career concerns & 3 & 0.90 & 4 & 0.84 \\
\hline Relationships at work & 2 & $0.46 \dagger$ & \multicolumn{2}{|c|}{ Excluded from this versio } \\
\hline
\end{tabular}

†Factors that have failed to achieve alpha coefficients of 0.7 or above. structure and content of the measure. Responses to this were noted in order to include any refinements in a subsequent draft.

\section{RESULTS}

Of the 105 questionnaires completed, four were discarded because of incomplete data. Principal components analysis (PCA) with varimax rotation was conducted on items $1-50$. PCA with varimax rotation is a statistical technique based on correlational principles which is applied to a single set of variables (questionnaire items) in order to highlight coherent subsets within the overall data set. In questionnaire design this technique is applied to identify the presence of domains (subscales reflecting different aspects of functioning) within a larger battery of items. The solution emerging from the PCA highlighted 10 principal factors with eigen values above 1.0 which accounted for $71.1 \%$ of the overall variance within the data set. An additional method of determining the relative importance of factors is the scree plot described by Cattell. ${ }^{12}$ This technique involves the graphical display of the descending variance accounted for by all the factors extracted by the analysis. The cut off point for this method is determined by the gradient of the slope. A scree plot confirmed the factors highlighted by the eigen values.

The factors identified were (1) physical functioning, mild to moderate impairment; (2) physical functioning, severe impairment; (3) social functioning; (4) treatment issues; (5) chest symptoms; (6) body image; (7) interpersonal relationships; (8) career concerns; (9) relationships at work; and (10) concerns for the future. The two physical functioning components were merged in order to create an overall domain of physical functioning which contained mild, moderate, and severe elements. The decision to do this was supported statistically by applying Cronbach alpha analysis to the merged physical functioning domain, the outcome of which indicated very good internal reliability (table 1 ). A single physical functioning domain is also clinically sensible and easily interpretable. With physical functioning merged into a single domain a total of nine domains of functioning remained.

Internal reliability of each domain was initially assessed using Cronbach alpha coefficients (table 1). Internal reliability is generally acceptable for factors with a Cronbach alpha coefficient of 0.7 or above. ${ }^{13}$ The exceptions to this were relationships at work, social functioning, and body image. These factors all contained items that were reworded slightly for subsequent versions, thereby eliminating ambiguities and leading to better reliability values. Because Cronbach alpha is influenced by the number of items in a domain, additional analyses using Pearson product moment correlation coefficients were conducted for all domains that contained only two items. Moderate to strong correlation coefficients emerged for treatment issues $(r=0.68)$, chest symptoms $(r$ $=0.73)$, body image $(r=0.52)$, and relationships at work $(r=0.55)$. Overall, items loaded cohesively onto the emergent factors. However, 
there were several ambiguities and, in order to maintain the integrity of the domains that the factors represented, 10 items were omitted from the next draft of the questionnaire.

The acceptability and face validity of the questionnaire was confirmed by (a) the patient's willingness to complete it, (b) positive comments regarding its content, (c) indication by the patients that they would be happy to complete and comment on subsequent versions of the measure, (d) failure of the screening item to reveal additional issues, and (e) positive reaction by all members of the multidisciplinary CF team about the content and its relationship to the overall measurement aims. The feedback provided by both patients and all members of the CF team raised an additional 15 items for inclusion in the subsequent CFQoL. This included a new section covering emotional responses to $\mathrm{CF}$. Patient feedback also led to the development of new response scales. For domains related to physical functioning, social functioning, chest symptoms, treatment issues and emotional responses, a six point Likert scale was applied with a range of $1=$ all of the time to $6=$ never, reflecting the fluctuating nature of $\mathrm{CF}$. A two week time scale was applied across these domains. For the remaining domains a modification of the original scale was applied with $1=$ strongly agree to $6=$ strongly disagree.

\section{Phase 2: Testing and validation of a second version of the CFQoL questionnaire}

METHODS

Thirty eight $\mathrm{CF}$ specific items were retained from the CFQoL1, either in their original form or in the reworded version, and the 15 new items were added to the second version of the questionnaire (CFQoL2). This generated a questionnaire with 53 items across nine domains of functioning.

\section{PATIENTS AND PROCEDURE}

The CFQoL2 questionnaire was completed by 223 adults with CF. The sample comprised 103 men and 120 women with a mean age of 25.2 years (range 14-52). Percentage of predicted forced expiratory volume in one second $\left(\mathrm{FEV}_{1}\right)$ was also calculated (mean $\mathrm{FEV}_{1}=$ $55 \%$, range $12-118 \%$ ). The CFQoL2 questionnaire was distributed to coincide with attendance at the outpatient clinic. Patients self-completed the measure and returned completed questionnaires by post. For purposes of assessing the concurrent validity of the CFQoL2, the Short Form 36 item (SF-36) Health Status questionnaire was distributed in parallel. The SF-36 is a generic health status measure that has been well tested and validated across a number of populations. ${ }^{14-17}$ It is one of the briefest measures currently in use, but is still one of the most comprehensive. ${ }^{14}$

RESULTS

Testing the structure of the CFQoL2 questionnaire was conducted by applying PCA with varimax rotation, Cronbach alpha coefficients, and item to domain correlations. The PCA indicated a solution consisting of eight factors on the basis of eigen values of 1.0 and above and the examination of the data from a scree plot. These were (1) chest symptoms, physical functioning (mild to moderate impairment) and social functioning; (2) emotional functioning; (3) interpersonal relationships; (4) concerns for the future; (5) career concerns; (6) treatment issues; (7) physical functioning (severe impairment); and (8) body image.

For those factors with an eigen value below 2.0 (career concerns, treatment issues, and body image) an additional screening measure was used. The percentage of adults with CF who responded negatively across domains provided a measure of "importance to patients". A negative response to domains is indicated by a raw score of 3 or less and is indicative of the difficulties patients are experiencing; $43 \%$ of patients responded negatively with regard to career concerns, $19 \%$ regarding treatment issues, and $29 \%$ concerning body image, so the retention of these domains was also warranted.

Physical functioning emerged as two factors that were again merged into a single domain. The rationale for this was that physical functioning is more easily interpreted and clinically sensible as a continuum of severity. Additionally, treating mild and moderate physical functioning separately from severe physical functioning may serve to generate floor and ceiling effects across each of these domains. For example, more severely affected individuals are likely to generate floor effects in the mild to moderate range whereas healthier individuals would generate ceiling effects across the severe range of items. Merging of the items serves to buffer this effect while still being sensitive to a range of disability across individuals. Statistical review supported this decision given that the Cronbach alpha coefficients (table 1) and the item to domain correlations (table 2) indicated that the domain was structurally robust. Item to domain correlations test whether items display a stronger correlation with the total domain score from their related domain compared with unrelated domains. To prevent overfitting of the item with related domain scores, the score from the item being considered was removed from the total domain score.

Also loading on to factor 1 were items that had previously emerged as separate factors (chest symptoms and social functioning). Treating these factors as a single domain may serve to confuse interpretability. Amalgamation of these items would lead to a loss of this specificity and the ability to respond in a clinical context. Cronbach alpha values (table 1) and item to domain correlations (table 2) demonstrated the integrity of the chest symptoms and social functioning domains as independent constructs. Because only two items were included in the chest symptoms domain a correlation analysis was conducted, the outcome of which revealed a strong relationship $(r=$ $0.72)$.

On the basis of the statistical and clinical interpretation of the data, the following nine final domains of functioning were identified: 
Table 2 Item to domain correlations for the CFQoL2 data

\begin{tabular}{|c|c|c|c|c|c|c|c|c|c|}
\hline Item no & $P F$ & $S F$ & $T I$ & $C S$ & $E R$ & $B I$ & $I R$ & $C I$ & $F C$ \\
\hline PF1 & 0.78 & 0.59 & 0.43 & 0.61 & 0.50 & 0.21 & 0.40 & 0.42 & 0.15 \\
\hline PF2 & 0.82 & 0.67 & 0.53 & 0.58 & 0.56 & 0.18 & 0.39 & 0.39 & 0.15 \\
\hline PF3 & 0.77 & 0.59 & 0.43 & 0.55 & 0.49 & 0.11 & 0.30 & 0.35 & 0.11 \\
\hline PF4 & 0.72 & 0.56 & 0.40 & 0.49 & 0.48 & 0.11 & 0.31 & 0.33 & 0.16 \\
\hline PF5 & 0.54 & 0.44 & 0.34 & 0.42 & 0.37 & 0.11 & 0.22 & 0.19 & 0.13 \\
\hline PF6 & 0.72 & 0.59 & 0.44 & 0.48 & 0.48 & 0.16 & 0.37 & 0.33 & 0.15 \\
\hline PF7 & 0.71 & $0.75^{\star}$ & 0.51 & 0.50 & 0.57 & 0.14 & 0.44 & 0.37 & 0.16 \\
\hline PF8 & 0.72 & 0.54 & 0.42 & 0.57 & 0.47 & 0.26 & 0.36 & 0.36 & 0.11 \\
\hline PF9 & 0.76 & 0.62 & 0.55 & $0.71^{\star}$ & 0.61 & 0.22 & 0.39 & 0.40 & 0.18 \\
\hline PF10 & 0.83 & 0.72 & 0.56 & 0.69 & 0.68 & 0.22 & 0.45 & 0.44 & 0.22 \\
\hline SF1 & 0.61 & 0.72 & 0.56 & 0.47 & 0.56 & 0.16 & 0.43 & 0.30 & 0.20 \\
\hline SF2 & $0.72^{\star}$ & 0.79 & 0.49 & 0.53 & 0.59 & 0.12 & 0.39 & 0.33 & 0.20 \\
\hline SF3 & 0.70 & 0.86 & 0.51 & 0.55 & 0.63 & 0.18 & 0.49 & 0.33 & 0.23 \\
\hline SF4 & 0.67 & 0.75 & 0.64 & 0.62 & 0.69 & 0.24 & 0.55 & 0.40 & 0.30 \\
\hline TI1 & 0.49 & 0.53 & 0.79 & 0.52 & 0.48 & 0.26 & 0.32 & 0.28 & 0.20 \\
\hline TI2 & 0.58 & 0.61 & 0.81 & 0.52 & 0.58 & 0.20 & 0.43 & 0.28 & 0.23 \\
\hline TI3 & 0.52 & 0.59 & 0.76 & 0.60 & 0.60 & 0.22 & 0.43 & 0.36 & 0.27 \\
\hline $\mathrm{CS} 1$ & $0.72^{\star}$ & 0.57 & 0.56 & 0.72 & 0.60 & 0.25 & 0.36 & 0.37 & 0.18 \\
\hline CS2 & 0.61 & 0.57 & 0.55 & 0.72 & 0.65 & 0.35 & 0.47 & 0.42 & 0.35 \\
\hline ER1 & 0.49 & 0.53 & 0.52 & 0.52 & 0.74 & 0.14 & 0.44 & 0.33 & 0.28 \\
\hline ER2 & 0.50 & 0.51 & 0.49 & 0.54 & 0.75 & 0.20 & 0.48 & 0.34 & 0.27 \\
\hline ER3 & 0.47 & 0.49 & 0.45 & 0.48 & 0.52 & 0.18 & 0.40 & 0.29 & 0.21 \\
\hline ER4 & 0.58 & 0.59 & 0.47 & 0.61 & 0.79 & 0.19 & 0.49 & 0.42 & 0.27 \\
\hline ER5 & 0.47 & 0.46 & 0.38 & 0.47 & 0.73 & 0.14 & 0.42 & 0.33 & 0.27 \\
\hline ER6 & 0.51 & 0.61 & 0.40 & 0.45 & 0.69 & 0.08 & 0.48 & 0.38 & 0.41 \\
\hline ER7 & 0.58 & 0.62 & 0.57 & 0.60 & 0.77 & 0.21 & 0.47 & 0.33 & 0.27 \\
\hline ER8 & 0.56 & 0.60 & 0.52 & 0.56 & 0.75 & 0.21 & 0.54 & 0.43 & 0.30 \\
\hline $\mathrm{FC} 1$ & 0.02 & 0.09 & 0.09 & 0.08 & 0.13 & 0.17 & 0.19 & 0.21 & 0.34 \\
\hline FC2 & 0.18 & 0.21 & 0.20 & 0.22 & 0.25 & 0.28 & 0.19 & 0.30 & 0.63 \\
\hline FC3 & 0.10 & 0.14 & 0.17 & 0.16 & 0.19 & 0.21 & 0.14 & 0.19 & 0.64 \\
\hline FC4 & 0.11 & 0.15 & 0.13 & 0.23 & 0.24 & 0.21 & 0.27 & 0.23 & 0.70 \\
\hline FC5 & 0.14 & 0.21 & 0.19 & 0.23 & 0.30 & 0.22 & 0.35 & 0.35 & 0.74 \\
\hline FC6 & 0.30 & 0.38 & 0.35 & 0.37 & 0.47 & 0.19 & 0.43 & 0.40 & 0.57 \\
\hline IR1 & 0.31 & 0.32 & 0.28 & 0.29 & 0.40 & 0.30 & 0.77 & 0.49 & 0.18 \\
\hline IR2 & 0.38 & 0.40 & 0.39 & 0.38 & 0.41 & 0.28 & 0.59 & 0.41 & 0.28 \\
\hline IR3 & 0.20 & 0.26 & 0.18 & 0.21 & 0.29 & 0.31 & 0.70 & 0.37 & 0.13 \\
\hline IR4 & 0.30 & 0.34 & 0.26 & 0.36 & 0.36 & 0.25 & 0.73 & 0.36 & 0.15 \\
\hline IR5 & 0.40 & 0.40 & 0.27 & 0.26 & 0.36 & 0.25 & 0.67 & 0.33 & 0.16 \\
\hline IR6 & 0.31 & 0.36 & 0.29 & 0.31 & 0.45 & 0.38 & 0.63 & 0.46 & 0.32 \\
\hline IR7 & 0.37 & 0.47 & 0.34 & 0.34 & 0.52 & 0.23 & 0.74 & 0.39 & 0.27 \\
\hline IR8 & 0.31 & 0.30 & 0.33 & 0.37 & 0.38 & 0.17 & 0.42 & 0.36 & 0.27 \\
\hline IR9 & 0.38 & 0.49 & 0.41 & 0.39 & $0.51^{\star}$ & 0.26 & 0.58 & 0.43 & 0.37 \\
\hline IR10 & 0.46 & 0.55 & 0.43 & 0.41 & 0.60 & 0.32 & 0.71 & 0.44 & 0.39 \\
\hline BI1 & 0.10 & 0.06 & 0.19 & 0.18 & 0.15 & 0.51 & 0.26 & 0.24 & 0.20 \\
\hline BI2 & 0.18 & 0.15 & 0.16 & 0.23 & 0.11 & 0.55 & 0.27 & 0.22 & 0.26 \\
\hline BI3 & 0.29 & 0.31 & 0.28 & 0.30 & 0.29 & 0.57 & 0.39 & 0.30 & 0.26 \\
\hline CI1 & 0.27 & 0.22 & 0.22 & 0.26 & 0.31 & 0.26 & 0.45 & 0.64 & 0.23 \\
\hline CI2 & 0.37 & 0.31 & 0.30 & 0.36 & 0.36 & 0.29 & 0.48 & 0.79 & 0.29 \\
\hline $\mathrm{CI} 3$ & 0.47 & 0.36 & 0.26 & 0.38 & 0.35 & 0.19 & 0.35 & 0.64 & 0.31 \\
\hline CI4 & 0.41 & 0.38 & 0.34 & 0.43 & 0.50 & 0.30 & 0.58 & 0.67 & 0.43 \\
\hline
\end{tabular}

Correlations with own domain are highlighted in bold.

${ }^{\star}$ Correlations with unrelated domains that are similar to or greater than intra domain correlations. $\mathrm{PF}=$ physical functioning; $\mathrm{SF}=$ social functioning; $\mathrm{TI}=$ treatment issues; $\mathrm{CS}=$ chest symptoms $\mathrm{ER}=$ emotional responses; $\mathrm{FC}=$ future concerns; $\mathrm{IR}=$ interpersonal relationships; $\mathrm{BI}=$ body image; $\mathrm{CI}=$ career issues. indicating that the CFQoL2 questionnaire had good concurrent validity with the appropriate domains of the SF-36 questionnaire.

DISCRIMINATION OF THE CFQOL2 QUESTIONNAIRE Method: patients and procedure

A method of assessing whether the measure can differentiate between patients with varying degrees of disease severity is to divide the population on the basis of percentage predicted $\mathrm{FEV}_{1} \cdot{ }^{18}$ The overall group of 223 patients given the CFQoL2 questionnaire were divided into three disease severity groups: mild disease ( $\mathrm{FEV}_{1} \geqslant 71 \%$ predicted), moderate disease ( $\mathrm{FEV}_{1}$ 41-70\% predicted), and severe disease $\left(\mathrm{FEV}_{1} \leqslant 40 \%\right.$ predicted). Domain comparisons between the groups were made using one way analysis of variance (ANOVA) with Tukey's honestly significant difference as a post hoc analysis for significant differences between groups.

\section{Results}

Significant main effects were observed for all domains: physical functioning $(\mathrm{F}=15.82$, $\mathrm{p}<0.000)$, social functioning $(\mathrm{F}=4.56$, $\mathrm{p}<0.01)$, treatment issues $(\mathrm{F}=4.44, \mathrm{p}<0.01)$, chest symptoms $(\mathrm{F}=11.68, \mathrm{p}<0.000)$, emotional responses $(F=4.64, p<0.01)$, concerns for the future $(\mathrm{F}=3.52, \mathrm{p}<0.03)$, interpersonal relationships $(\mathrm{F}=5.76, \mathrm{p}<0.003)$, body image $(\mathrm{F}=10.96, \mathrm{p}<0.000)$, career concerns $(\mathrm{F}=$ 5.33, $\mathrm{p}<0.005)$, and total scores $(\mathrm{F}=13.28$, $\mathrm{p}<0.000)$. Post hoc analysis demonstrated that the CFQoL2 discriminated between levels of disease severity in the following ways: (1) between mild and moderate disease for the domains of body image, interpersonal relationships, concerns for the future, and total CFQoL scores; (2) between moderate and severe disease for physical functioning, social functioning, and chest symptoms; and (3) between mild and severe disease for all domains except concerns for the future.

To compare the discriminatory validity of the SF-36 a series of ANOVAs were also applied to comparative domains as with the assessment of concurrent validity. Significant main effects occurred for total SF-36 scores (F $=5.04, \mathrm{p}<0.007)$ and for physical functioning $(\mathrm{F}=17.43, \mathrm{p}<0.000)$, with specific group differences between mild and severe groups for both domains and also between severe and moderate groups for the physical functioning domain. No group differences emerged for social functioning or mental health. These data indicated that the CFQoL had good discriminatory ability, particularly in comparison with the SF-36. established and well validated measure. The SF-36 questionnaire was completed by the 223 patients alongside the CFQoL2 questionnaire.

\section{Results}

Correlations between the two questionnaires were only made across similar domains: physical functioning $(r=0.73)$, social functioning $(r$ $=0.67)$, mental health/emotional functioning $(r=0.64)$, and total questionnaire scores $(r=$ $0.74)$. All of the correlations were moderate to strong and very highly significant $(\mathrm{p}<0.001)$,

\section{Phase 3: Test-retest reliability of the third version of the questionnaire} METHOD

On the basis of the analyses described in phase 2 , further minor amendments were made to the CFQoL resulting in a third and final version of the questionnaire consisting of 52 items across nine domains of functioning (appendix 1). The test-retest procedure measured the stability of scores on the CFQoL over time. If the 
questionnaire is administered at time point 1 and then again 7-10 days later, the scores should remain relatively unchanged for patients who report no change in health status. This is important in determining whether changes measured by a questionnaire are genuine or an artefact of chance fluctuations.

\section{PROCEDURE AND PATIENTS}

To test the external reliability of the measure, the third version of the CFQoL questionnaire was posted to 200 adults with CF. A second questionnaire was sent to be completed within 7-10 days of the first. This time period was chosen to be long enough not to introduce memory confounds while being short enough to prevent fluctuations in disease status. Patients were also sent a further questionnaire alongside the second distribution of the CFQoL questionnaire which asked them to what extent they felt their health had changed since the first completion of the measure. Only patients who stated no change in health status and who completed both questionnaires within 7-10 days were included in the analysis.

RESULTS

One hundred patients completed and returned the questionnaire. Of these only 32 (17 men) fitted the inclusion criteria. The mean age of responders was 27 years (men 28 years, women 26 years). The overall age range was $16-53$ years (men 18-40, women 16-53). Correlation analysis was applied to assess the degree of relationship between data completed at the two designated time points (table 3 ). The analysis indicated strong correlations $(r>0.8)$ and explained $72.9-92.2 \%$ of overall variance between pairs $\left(r^{2} \times 100\right)$. The only exception to this was for treatment issues $(r=0.74)$, explaining $55.2 \%$ of the variance. This indicated that the test-retest reliability for the CFQoL was robust.

\section{Phase 4: Sensitivity testing of the third version of the CFQoL \\ METHOD}

Sensitivity testing examines whether a measure is able to detect either deterioration in health status or improvements brought about by an intervention. HRQoL using the third and final version of the CFQoL questionnaire was assessed in patients presenting with a pulmonary exacerbation. It was anticipated that improvements in pulmonary function as determined by percentage predicted $\mathrm{FEV}_{1}$, and pos-

Table 3 Pearson correlation analysis of the test-retest data of the third version of the CFQoL

\begin{tabular}{lll}
\hline & $r$ & $r^{2} \times 100$ \\
\hline Physical functioning & 0.93 & $87.8 \%$ \\
Social functioning & 0.85 & $72.9 \%$ \\
Treatment issues & 0.74 & $55.2 \%$ \\
Chest symptoms & 0.93 & $86.3 \%$ \\
Emotional responses & 0.90 & $81.5 \%$ \\
Future concerns & 0.92 & $84.5 \%$ \\
Interpersonal relationships & 0.91 & $83.0 \%$ \\
Body image & 0.88 & $77.5 \%$ \\
Career issues & 0.95 & $91.0 \%$ \\
Total CFQoL score & 0.96 & $92.2 \%$ \\
\hline
\end{tabular}

Table 4 Displaying the results of the pre and post treatment analyses

\begin{tabular}{llll}
\hline & t value & p value & Effect size \\
\hline FEV 1 (\% predicted) & 4.90 & $0.000^{\star \star \star}$ & 1.39 \\
BMI & 2.78 & $0.01^{\star \star}$ & 0.78 \\
Physical functioning & 3.48 & $0.002^{\star \star}$ & 0.98 \\
Social functioning & 2.88 & $0.009^{\star \star}$ & 0.81 \\
Treatment issues & 1.99 & $0.059+$ & 0.56 \\
Chest symptoms & 5.98 & $0.000^{\star \star \star}$ & 1.69 \\
Emotional responses & 3.91 & $0.001^{\star \star \star}$ & 1.10 \\
Concerns for the future & 2.83 & $0.009^{\star \star}$ & 0.80 \\
Interpersonal relationships & 3.40 & $0.002^{\star \star}$ & 0.96 \\
Body image & 3.23 & $0.004^{\star \star}$ & 0.91 \\
Career & 2.10 & $0.047^{\star}$ & 0.59 \\
Total CFQoL scores & 6.90 & $0.000^{\star \star \star}$ & 1.95 \\
\hline
\end{tabular}

$\mathrm{tp}<0.10 ;{ }^{\star} \mathrm{p}<0.05 ;{ }^{\star \star} \mathrm{p}<0.01 ;{ }^{\star \star \star} \mathrm{p}<0.001$.

sibly small changes in body mass index (BMI), would have occurred by the end of the treatment period.

PATIENTS AND PROCEDURE

Patients presenting at the clinic over a four month period who were diagnosed by the attending physician as presenting with an exacerbation of chest symptoms consented to participate in the study. Data were collected from 24 patients (nine men) of mean age 23 years (range 16-48). Participants completed the CFQoL questionnaire on diagnosis (time point 1) and again at the end of a two week period of intravenous antibiotic treatment (time point 2). Also collected at each time point were $\mathrm{FEV}_{1}$ and height and weight in order to calculate percentage predicted $\mathrm{FEV}_{1}$ and BMI.

RESULTS

Each domain was analysed separately by applying a series of related $t$ tests and calculating the effect size of the change between time point 1 and time point 2 . The analyses revealed a range of significant differences with large effect sizes for clinical status across the majority of domains (table 4). Higher values were attained at the second time point indicating an improvement in function.

\section{Scoring and interpretation of scores}

The scoring scales were designed to reflect positive and negative scoring. All items were scored 1 to 6 , with the exception of item 6 ("Despite CF, over the last two weeks I have got around and done what I like") which is reverse scored 6 to 1 . Raw scores of 3 or under indicate a negative response. Transformed domain scores of 50 or less also indicate negative responses and suggest that the individual may be experiencing difficulties within that particular domain. Transformed scores translate to values between 0 and 100 and are achieved by following the equations outlined in appendix 2. A transformed score indicates the value that has been achieved out of a maximum of 100 with 100 indicating the most positive QoL levels possible.

\section{Discussion}

The CFQoL questionnaire is a valid and reliable measure of HRQoL for adults and adolescents with CF. It is a patient derived measure which includes domains and response 
scales that have been determined by the patients and are therefore meaningful to them. Within each domain are sets of items, each of which tap into specific areas of HRQoL issues of importance to adults with CF. The outcome of this is that these can be assessed on a domain by domain basis or, more specifically, on an item by item basis if individual issues are to be evaluated in a therapeutic context. Response rates of $98 \%$ for face to face completion and $54 \%$ for postal means suggests a good compliance rate for the CFQoL.

Given that no attempt was made to eliminate sex biased questions from the measure, the CFQoL questionnaire will be able to identify disparities in HRQoL between men and women, should they exist. If items had been eliminated on the basis of sex differences important issues based on group membership may have been missed. It is important that sex is considered separately in health issues, as there is a wealth of literature that suggests that men and women respond very differently to poor health. ${ }^{19-23}$ Women generally report higher levels of physical disease, more pain, and more subjective or emotional symptoms than men. It is recommended that an initial analysis on the basis of sex should always be conducted, although where sex differences are not observed it is reasonable to proceed with a global analysis of the data.

The analysis of the CFQoL questionnaire has suggested that it may be appropriate for several different applications. Firstly, the data relating to the sensitivity of the CFQoL questionnaire have indicated that the measure is able to detect transient changes in health status. This is relevant for use in clinical trials (both medical or psychosocial in nature). Secondly, it is suitable for cross sectional comparison of groups given that it detected differences based on group membership which reflected varying levels of disease severity in adults with CF. Thirdly, the questionnaire would be useful in describing the longitudinal changes that take place in adults with $\mathrm{CF}$ as a function of progression and deterioration in disease status. The measure would be usefully applied at annual reviews, or even more frequently as the health of the patient begins to decline more rapidly. This would provide useful natural data for assessing the outcomes of various interventions including heart-lung transplantation, for which few baseline data have been collected in the existing studies, ${ }^{24-26}$ and also for end point stages in the terminal phase of the disease. Finally, the CFQoL questionnaire will also be useful on an individual basis to identify and intervene where problems are evidenced. This would provide a valuable adjunct to the diagnostic approaches already available, highlighting poor functioning on a wider level than merely physiological and serving to highlight areas that would be open to intervention on a more psychosocial level alongside the traditional medical interventions.

1 UK Cystic Fibrosis Survey 1993 Report. Bromley, Kent: The Cystic Fibrosis Trust, 1993.

2 Super M, Abbott J. Genetic advances in cystic fibrosis: to screen, to treat or both? Disability Rehabil 1998;20:202-8.

3 Orenstein DM, Nixon PA, Ross EA, et al. The quality of well-being in cystic fibrosis. Chest 1989;95:344-7.

4 Kaplan RM, Anderson JP, Wu AW, et al. D. The quality of well being scale: applications in AIDS, cystic fibrosis and arthritis. Medical Care 1989;27:S27-43.

5 Shepherd SL, Hovell MF, Slymen DJ, et al. Functional status as an overall measure of health in adults with cystic fibrosis: further validation of a generic health measure. $f$ Clin Epidemiol 1992;45:117-25.

6 Weir DC, Freeman W, Roberts KT, et al. Comparison of the measure of quality of life in patients with cystic fibrosis CF) and chronic airflow obstruction (CAO). Thorax 1991;46:288.

7 Alonso J, Anto JM, Gonzalez M, et al. Measurement of general health status of non-oxygen dependent chronic obstructive pulmonary disease patients. Medical Care 1992; 30(Supplement): MS125-35.

8 Anderson KL. The effect of chronic obstructive pulmonary disease on quality of life. Res Nursing Health 1995;18:54756.

9 Congleton J, Hodson M, Duncan-Skingle F. Quality of life in adults with cystic fibrosis. Thorax 1997;52:397-400.

10 Abbott J, Dodd M, Webb AK. Coping styles and treatment adherence in adults with cystic fibrosis. 21st European Cystic Fibrosis Conference, Davos, Switzerland, 1997.

11 Creer TL, Wignal JK, Kotses $\mathrm{H}$, et al. A life activities questionnaire for adult asthma. F Asthma 1992;29:393-9.

12 Cattell RB. The meaning and strategic use of factor analysis. In: Cattell RB, ed. Handbook of multivariate experimental psychology. Chicago: Rand McNally: 1966.

13 Nunally JC. Psychometric theory. In: Jenkinson C, Layte R, Coulter A, et al. Evidence for the sensitivity of the SF-36 health status measure to inequalities in health: results from the Oxford healthy lifestyles survey. F Epidemiol Community Health 1996;50:377-80.

14 Brazier JE, Harper R, Jones NMB, et al. Validating the SF36 health survey questionnaire: new outcome measure for primary care. BMF 1992;305:160-4.

15 Jenkinson C, Wright L, Coulter A. Quality of life measurement in health care. A review of measures and population norms for the UK SF-36. Health Services Research Unit, 1993.

16 Roberts R, Hemingway H, Marmot M. Psychometric and clinical validity of the SF-36 general health survey in the Whitehall II study. Br f Health Psychol 1997;2:285-300.

17 Garratt AM, Ruta DA, Abdalla MI, et al. The SF36 health survey questionnaire: an outcome measure suitable for routine use within the NHS? BMF 1993;306:1440-4.

18 Fiel SB, FitzSimmons S, Schidlow D. Evolving demographics of cystic fibrosis. Semin Respir Crit Care Med 1994;15:349-55.

19 Mechanic D. Sex, illness, illness behaviour and the use of health services. Soc Sci Med 1978;128:207-14.

20 Merril SS, Seeman TE, Kasl SV, et al. Gender differences in the comparison of self reported disability and performance measures. F Gerontol: Med Sci 1997;52a:M19-26.

21 Piccinelli M, Simon G. Gender and cross cultural differences in somatic symptoms associated with emotional distress: an international study in primary care. Psychol Med 1997;27:433-44

22 Unruh AM. Gender variations in clinical pain experience. Pain 1996;65:123-67.

23 Ruiz MT, Verbrugge L. A two way view of gender bias in medicine. F Epidemiol Community Health 1997;51:106-9.

24 Yacoub MH, Banner NR, Khaghani A, et al. Heart-lung transplant for cystic fibrosis and subsequent domino heart transplantation. F Heart Transplant 1990;9:459-67.

25 Busschbach JJV, Horikx PE, van den Bosch JMM, et al. Measuring the quality of life before and after bilateral lung Measuring the quality of life before and after bilateral lung 105:911-7.

26 Barbers RG. Cystic fibrosis: bilateral living lobar vs cadaveric lung transplantation. Am f Med Sci 1988;315: $155-60$. 


\section{Appendix 1: Final version of the CFQoL}

The Cystic Fibrosis Quality of Life Questionnaire.

The following questionnaire is designed to find out how CF affects your life. Read each statement, and then indicate which response is closest to how you feel, by ticking $(\checkmark)$ one of the boxes after each statement. Please try to answer ALL the questions, as honestly as you can.

SECTION ONE:

How often, over the last two weeks, do you feel that your CF has affected the following aspects of your physical functioning/mobility?

1. Because of my CF, During the last two weeks, I have had difficulty doing heavy physical jobs. For example, digging, moving furniture, washing the car, vacuuming etc.

All of the time

$\square \quad \square$

During the last two weeks, my CF has prevented me from getting out of the house to run errands. For example, paying bills, posting a letter, doing light shopping etc.

3. Because of my CF, over the last two weeks, it has been difficult for me to do light tasks around the house. For example, preparing a light snack, washing up, picking up the mail etc.

\begin{tabular}{|c|c|c|c|c|c|}
\hline All of the time & $\begin{array}{l}\square \\
\text { most of the time }\end{array}$ & $\begin{array}{l}\square \\
\text { good bit of the time }\end{array}$ & $\begin{array}{l}\square \\
\text { sometimes }\end{array}$ & $\begin{array}{l}\square \\
\text { occasionally }\end{array}$ & $\begin{array}{l}\square \\
\text { never }\end{array}$ \\
\hline 口 & $\square$ & 口 & 口 & $\square$ & $\square$ \\
\hline All of the time & most of the time & good bit of the time & sometimes & occasionally & never \\
\hline$\square$ & $\square$ & $\square$ & $\square$ & $\square$ & $\square$ \\
\hline All of the time & most of the time & good bit of the time & sometimes & occasionally & never \\
\hline \multicolumn{6}{|c|}{ Despite CF, over the last two weeks I have got around and done what I like. } \\
\hline \multicolumn{6}{|c|}{ During the last two weeks, there are places that I would like to have gone but didn't because of my CF. } \\
\hline ㅁ & 口 & 口 & $\square$ & 口 & $\square$ \\
\hline All of the time & most of the time & good bit of the time & sometimes & occasionally & never \\
\hline \multicolumn{6}{|c|}{ My CF has limited the type of sports and exercise I have been able to do over the last two weeks. } \\
\hline$\square$ & $\square$ & 口 & 口 & $\square$ & ㅁ \\
\hline All of the time & most of the time & good bit of the time & sometimes & occasionally & never \\
\hline \multicolumn{6}{|c|}{. During the last two weeks, my CF has made me feel lacking in energy. } \\
\hline
\end{tabular}

SECTION TWO

Over the past two weeks, has CF affected your social life in any of the following ways?

11. When I have been out socialising, over the last two weeks, I have behaved more cautiously than I would like to because of my CF.

11. Whe

$\begin{array}{lll}\square & \square & \square \\ \text { All of the time } & \text { most of the time } & \text { good bit of the time }\end{array}$

12. Because of my CF, during the last two weeks, I have tended to avoid visiting friends.

$\begin{array}{lll}\square & \square & \text { most of the time }\end{array}$

All of the time most of the time good bit of the time
3. For the last two weeks, I have avoided going out and socialising because of my CF.

. For the last two weeks,

All of the time most of the time good bit of the time sometimes

14. I find that the way in which CF affects my socialising interferes with my overall enjoyment of life.

$\square \quad \square \quad \square \quad \square$

All of the time most of the time good bit of the time sometimes metimes

$\square$

occasionally never

(n)

$\square$

The following questions ask you about symptom and treatment aspects of your CF. How have the following factors affected you over the last two weeks?

15. Over the last two weeks, I have found my treatments (ie physio, enzymes etc) very time consuming.

All

A

ㅁ $\quad$ (

most of the time good bit of the time sometimes
16. During the last two weeks, my treatments have interfered with other things that I have wanted to do.

$\square \quad \square \quad \square \quad \square$

All of the time_most of the time good bit of the time sometimes

17. Over the last two weeks, I have found that my treatments have interfered with my enjoyment of life.

All of the time most of the time good bit of the time sometimes

18. I have found my breathlessness troublesome, during the last two weeks.

$\square \quad \square \quad \square \quad$ most of the time

sometimes

19. Over the last two weeks, I have found my coughing troublesome.

All of the time most of the time good bit of the time
20. I have found my coughing embarrassing over the last two weeks.

$\square \quad \square \quad \square \quad \square$

21. For me, over the past two weeks, breathlessness / coughing have made life less enjoyable.

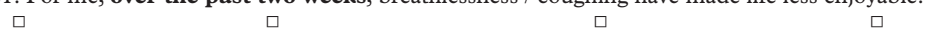

$\square$ (

SECTION FOUR:

most of the time good bit of the time sometimes

occasionally never

Over the past two weeks, I have found that my CF has made me feel:

22. Resentful:

ㅁ

All of the time

$\square$

$\square \quad \square$

23. Angry:

$\square$

most of the time

good bit of the time

sometimes

$\square$

occasionally never

All of the time

most of the time

good bit of the time

$\square$

24. Embarrassed:

$\square \quad$

good bit of the time

sometimes

good bit of the time sometimes

All of the time

most of the time

25. Irritable:

All of the time most of the time

26. So fed up that nothing can cheer me up:

All of the time most of the time

$\square$

good bit of the time sometimes

$\begin{array}{ll}\square & \square \\ \text { occasionally } & \text { never } \\ \square & \square \\ \text { occasionally } & \text { never } \\ \square & \square \\ \text { occasionally } & \text { never } \\ \square & \square \\ \text { occasionally } & \text { never } \\ \square & \square \\ \text { occasionally } & \text { never } \\ \square & \square \\ \text { occasionally } & \text { never } \\ \square & \square \\ \text { occasionally } & \text { never }\end{array}$

$\square \quad \square$

good bit of the time sometimes

sometimes

$\begin{array}{ll}\square & \square \\ \text { occasionally } & \text { never } \\ \square & \square \\ \text { occasionally } & \text { never } \\ \square & \square \\ \text { occasionally } & \text { never } \\ \square & \square \\ \text { occasionally } & \text { never } \\ \square & \square \\ \text { occasionally } & \text { never }\end{array}$




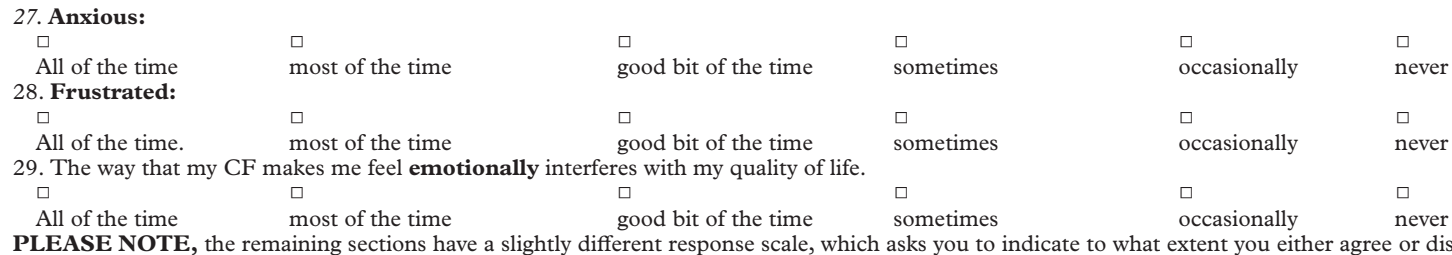

PLEASE NOTE, the remaining sections have a slightly different response scale, which asks you to indicate to what extent you either agree or disagree with each statement. Again, indicate which response is the closest to how you feel by ticking $(\checkmark)$ one of the boxes after each statement. Please try to answer ALL questions as honestly as possible.

\section{SECTION FIVE:}

The next section asks you about any concerns that you may have for the future because of your CF:

30. It concerns me that I may not be able to have any/have more children.

\begin{tabular}{|c|c|c|c|c|c|}
\hline 口 & ㅁ & $\square$ & ㅁ & $\square$ & $\square$ \\
\hline Strongly agree & Agree & Slightly agree & Slightly disagree & Disagree & Strongly disagree \\
\hline \multicolumn{6}{|c|}{ 31. I have concerns about being assessed for a heart-lung transplant. } \\
\hline$\square$ & $\square$ & $\square$ & $\square$ & $\square$ & ㅁ \\
\hline Strongly agree & Agree & Slightly agree & Slightly disagree & Disagree & Strongly disagree \\
\hline \multicolumn{6}{|c|}{ 32. The possibility of needing a heart-lung transplant worries me. } \\
\hline 口 & $\square$ & ㅁ & 口 & 口 & ㅁ \\
\hline Strongly agree & Agree & Slightly agree & Slightly disagree & Disagree & Strongly disagree \\
\hline \multicolumn{6}{|c|}{ 33. I worry about CF shortening my life. } \\
\hline$\square$ & $\square$ & ㅁ & $\square$ & $\square$ & 口 \\
\hline Strongly agree & Agree & Slightly agree & Slightly disagree & Disagree & Strongly disagree \\
\hline \multicolumn{6}{|c|}{ 34. In general thinking about the future makes me feel concerned / worried. } \\
\hline 口 & $\square$ & ㅁ & $\square$ & ㅁ & 口 \\
\hline Strongly agree & Agree & Slightly agree & Slightly disagree & Disagree & Strongly disagree \\
\hline \multicolumn{6}{|c|}{ 35. The worries that I have about the future make life less enjoyable. } \\
\hline$\square$ & $\square$ & $\square$ & ㅁ & $\square$ & $\square$ \\
\hline Strongly agree & Agree & Slightly agree & Slightly disagree & Disagree & Strongly disagree \\
\hline
\end{tabular}

SECTION SIX:

In general , do you agree or disagree that your CF has affected your relationships with other people in any of the following ways? 36. Establishing new relationships / friendships is difficult because of my CF.

$\square$

$\square \quad \square$

Strongly agree Agree
37. I find that my friends don't always understand the limits that my CF places on me.

$\begin{array}{llll}\square & \square & \square & \square \\ \text { Strongly agree } & \text { Agree } & \text { Slightly agree } & \text { Slight }\end{array}$

38. My CF makes it difficult for me to establish intimate relationships.

$\square \quad \square \quad \square \quad \square$

Strongly agree Agree
39. My CF makes it difficult for me to maintain intimate relationships.

$\begin{array}{lll}\text { 39. My CF makes it difficult for me to maintain intimate relationships. } \\ \square & \square & \square \\ \text { Strongly agree } & \text { Agree } & \text { Slightly agree }\end{array}$

Strongly agree
40. I find that my CF interferes with me having a satisfactory sex life.
$\square$

Strongly agree Agree Slightly agree

41. I find that CF makes me feel different from other people my own age.

$\square \quad \square \quad \square$

Strongly agree Agree Slightly agree

$\begin{array}{ll} & \square \\ & \text { Disagree }\end{array}$

$\square \quad \square$

trongly disagree

Strongly disagree

42. My CF makes me feel isolated from other people.

Strongly agree

Strongly agree Agree Slightly agree

43. I am concerned that my CF is stressful for those who are close to me.

$\square \quad \square \quad$ A

Strongly agree Agree Slightly agree

44. I worry that, because of my CF, I will never be able to lead an independent life.

$\square \quad \square$

Strongly agree Agree Slightly agree

Strongly agree
45. The way in which CF affects my relationships with other people interferes with my

SECTION SEVEN:

Agree Slightly agree

Disagree

Slightly disagree Disagree $\quad$ Strongly disagree

$\square \quad \square \quad \square$

Strongly disagree

$\mathrm{CF}$ can affect your height/weight, in general how has this made you feel?

46. I believe that my CF has made me too small.

$\square \quad \square \quad \square \quad$ A $\quad \square$ (

Strongly agree Agree
47. I feel that because of my CF I am too thin

7. I feel that because of my

Slightly agree Slightly disagree

Slightly agree Slightly disagree $\quad$ Disagree $\quad$ Strongly disagree

. The way that my CF has made me look because of my height / weight makes life less enjoyable.

Strongly agree $\quad$ Agree $\quad$ Slightly agree Slightly disagre

Slightly disagre

Strongly disagree

$\square$

Strongly disagree

Slightly disagree

Disagree

Strongly disagree

Slightly disagree Disagree

$\square$

Strongly disagree

$\square$

Strongly disagree

Strongly disagree

SECTION EIGHT:

The next section asks you about problems you may experience at college, work OR school as a result of your CF. If you are no longer working or at college, please answer the questions in relation to your past experiences.

49. $\mathrm{CF}$ makes/has made, finding a suitable college course/job difficult.

. CF makes/has made, fir

Strongly agree $\quad \square \quad \square$

50. Holding down a job / college course is / has been difficult because of my CF.

$\square \quad \square \quad \square$

Strongly agree Agree $\quad$ mork / go to college because of my CF.

$\square \quad \square \quad$ Agree

Strongly agree Agree
52. I find that CF interferes with my career / college OR school

Thank you for completing the questionnaire

(1)

Slightly disagree Disagree $\quad$ Strongly disagree

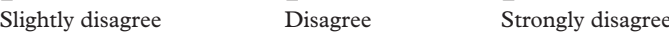

$\begin{array}{lll}\square & \square & \square \\ \text { Slightly disagree } & \text { Disagree } & \text { Strongly disagree }\end{array}$

ol life to such an extent that it makes life less enjoyable.

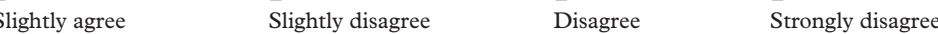




\section{Appendix 2: Scoring equations} SECTION 1: PHYSICAL FUNCTIONING

Please note that item 6 in this section is reverse scored. All other items throughout the questionnaire are scored 1 to 6 with the exception of this item which is scored 6 to 1 .

Physical functioning has 10 items, therefore a score of between 0 and 100 will be derived by adding all 10 items $(10 / 50 \times 100)$.

SECTION 2: SOCIAL FUNCTIONING

Social functioning has 4 items therefore a score of between 0 and 100 will be derived by adding all 4 items $(4 / 20 \times 100)$.

SECTION 3: TREATMENT ISSUES AND CHEST

SYMPTOMS

Treatments issues has 3 items therefore a score of between 0 and 100 will be derived by adding all 3 items $(3 / 15 \times 100)$.

Chest symptoms has 4 items therefore a score of between 0 and 100 will be derived by adding all 4 items $(4 / 20 \times 100)$.
SECTION 4: EMOTIONAL FUNCTIONING

Emotional functioning has 8 items therefore a score of between 0 and 100 will be derived by adding all 8 items $(8 / 40 \times 100)$.

SECTION 5: CONCERNS FOR THE FUTURE

Concerns for the future has 6 items therefore a score of between 0 and 100 will be derived by adding all 6 items $(6 / 30 \times 100)$

SECTION 6: INTERPERSONAL RELATIONSHIPS

Interpersonal relationships has 10 items therefore a score of between 0 and 100 will be derived by adding all 10 items $(10 / 50 \times 100)$.

SECTION 7: BODY IMAGE

Body image has 3 items therefore a score of between 0 and 100 will be derived by adding all 3 items (3/15 $\times 100)$.

SECTION 8: CAREER CONCERNS

Career concerns has 4 items therefore a score of between 0 and 100 will be derived by adding all four items $(4 / 20 \times 100)$. 